\title{
Experimental Analysis on Flexural-tensile Performance of Polyester Fiber Asphalt Concrete
}

\author{
Faqi Chen ${ }^{1}$, Chunshui Huang ${ }^{2,3 *}$, Jun Wang ${ }^{2}$, Danying Gao ${ }^{4}$ \\ ${ }^{1}$ Henan Dezheng Highway Co., Ltd., Kaifeng 475000, China \\ ${ }^{2}$ College of Civil Engineering, Xuchang University, Xuchang, 461000, China \\ ${ }^{3}$ School of Civil Engineering, Zhengzhou University, Zhengzhou 450000, China \\ ${ }^{4}$ Henan University of Engineering, Zhengzhou 450000, China
}

Corresponding Author Email: chunshuihuang@163.com

https://doi.org/10.18280/acsm.430203

Received: 15 January 2019

Accepted: 2 April 2019

\section{Keywords:}

polyester fiber asphalt concrete, flexuraltensile strength, fiber aspect ratio, fiber volume ratio, fiber content feature parameter $(F C F P)$

\begin{abstract}
Taking the AC-13F mixture as the matrix, this paper carries out beam bending tests on fiber asphalt concrete, using the optimal asphalt content (OAC) determined by Marshall test. The test parameters include temperature, fiber volume ratio and fiber aspect ratio. Based on the test results, the author systematically explored how the three parameters affect the flexural performance of asphalt concrete. In addition, the fiber content feature parameter (FCFP) was introduced to describe the combined effect of fiber volume ratio and fiber aspect ratio on the flexural performance of asphalt concrete, and an FCFP-based model was set up to calculate the flexural performance of polyester fiber reinforced concrete beams at different temperatures. The results show that the flexural-tensile strength of fiber asphalt concrete increases first and then decreases with the rising temperature; the failure strain of fiber asphalt concrete increases with temperature; under different temperatures, the flexural-tensile strength of polyester fiber asphalt concrete increases first and then decreases with the growth in fiber volume ratio or fiber aspect ratio; the optimal FCFP of polyester fibers is 1.13. The research findings shed important new light on flexural-tensile performance of polyester fiber asphalt concrete.
\end{abstract}

\section{INTRODUCTION}

The cracking of asphalt concrete pavement may occur due to the lack of flexural-tensile strength or the accumulation and development of meso-structure deformation. In this case, water will penetrate through the cracks and erode the interface between the asphalt and the aggregate. Prolonged exposure to moisture can de-bond the aggregate from the asphalt, which is a major cause of early damage of asphalt concrete pavement.

The asphalt concrete beam bending test offers an important way to study the low-temperature crack resistance of asphalt concrete $[1,2]$. A comprehensive index system has been developed for the bending tests on intact and pre-cracked asphalt concrete beam at different temperatures, and adopted to explore how the low-temperature crack resistance of asphalt concrete is affected by temperature, grading, asphaltaggregate ratio and loading rate. The index system mainly involves indices like the flexural-tensile strength, the strain and stiffness modulus at flexural-tensile failure (hereinafter referred to as failure stiffness modulus and failure strain), the J-integral, and the critical strain energy density [3-5]. With the development of computer technology, the bending test results have been simulated on finite-element, discrete-element and boundary element analysis software, aiming to disclose the correlation between the meso-structure and macroscopic mechanical performance of asphalt concrete [6].

Fiber asphalt concrete has received more and more attention, thanks to its excellent pavement performance and mechanical performance. Some progress has been made in the research of the flexural performance of this type of asphalt concrete. For instance, Reference [7] examines the impact of fiber type on the low-temperature crack resistance of fiber asphalt concrete through beam bending test. Reference [8] evaluates the resistance of glass fiber reinforced asphalt overlay to cracking and crack propagation, in light of fracture potential and critical strength. Reference [9] carries out a low-temperature beam bending test to disclose the effects of fiber content on lowtemperature performance of fiber asphalt concrete. The mechanism for the low-temperature crack resistance of fiber asphalt concrete has also been discussed, and the lowtemperature performance of fiber asphalt concrete has been evaluated based on the bending test index system [10-16].

Nevertheless, the existing studies have not tackled the following issues: the temperature induced-variations in the load at flexural-tensile failure (hereinafter referred to as the failure load), flexure-tensile strength, failure stiffness modulus and failure strain of fiber asphalt concrete; the relationship between bending test parameters of fiber asphalt concrete and the ratio of fiber volume to the volume of asphalt mixture (fiber volume ratio, $V_{f}$ ); the impact from the ratio of mean fiber length to mean fiber diameter (fiber aspect ratio $R_{a}$ ) to the flexural performance of asphalt concrete; the combined effect of fiber volume ratio and fiber aspect ratio on the flexural performance of asphalt concrete.

Taking the AC-13F mixture as the matrix, this paper carries out beam bending tests on fiber asphalt concrete, using the optimal asphalt content (OAC) determined by Marshall test. The test parameters include temperature, fiber volume ratio and fiber aspect ratio. Based on the test results, the author systematically explored how the three parameters affect the 
flexural performance of asphalt concrete. In addition, the fiber content feature parameter (FCFP) was introduced to describe the combined effect of fiber volume ratio and fiber aspect ratio on the flexural performance of asphalt concrete, and an FCFPbased model was set up to calculate the flexural performance of polyester fiber reinforced concrete beams at different temperatures.

\section{MATERIALS AND TESTS}

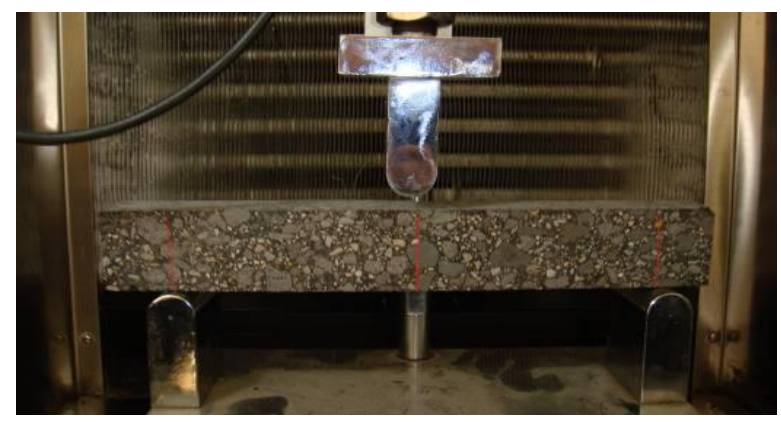

Figure 1. Bending test of small beam

Our tests use China's No.70 A-grade petroleum asphalt, and polyester fibers with a mean diameter of $18.5 \mu \mathrm{m}$. To disclose the effects of fiber volume ratio and fiber aspect ratio, the polyester fibers were tested at different aspect ratios (i.e. 162, 486 and 649$)$ at the same volume ratio $(0.35 \%)$, and also tested at different volume ratios (i.e. $0.17 \%, 0.35 \%, 0.52 \%$ and $0.69 \%$ ) at the same aspect ratio (324). The aggregate was sieved, cleaned, dried and then mixed with limestone powder, using the median value of AC- $13 \mathrm{~F}$ grading. Then, the OACs [17] of the base asphalt mixture and the fiber asphalt mixture were determined through Marshall test. In light of the OACs, the mixture was compacted into $300 \mathrm{~mm} \times 300 \mathrm{~mm} \times 500 \mathrm{~mm}$ asphalt concrete slabs, which was then cut into $250 \mathrm{~mm} \times 30$ $\mathrm{mm} \times 35 \mathrm{~mm}$ specimens. As shown in Figure 1, 3-point bending tests were carried out on a multi-functional material testing machine at temperatures of $-30{ }^{\circ} \mathrm{C},-20{ }^{\circ} \mathrm{C},-10{ }^{\circ} \mathrm{C}, 0{ }^{\circ} \mathrm{C}$ and $15{ }^{\circ} \mathrm{C}$ and the loading rate of $50 \mathrm{~mm} / \mathrm{min}$. In each group of tests, four specimens were tested in parallel and the measured data were averaged as the final test result.

According to the bending test results, the flexural-tensile strength $R_{B}$, the failure strain $\varepsilon_{B}$, and the failure stiffness modulus $S_{B}$ [17]:

$$
\begin{gathered}
R_{B}=\frac{3 L P_{B}}{2 b h^{2}} \\
\varepsilon_{B}=\frac{6 h d}{L^{2}} \\
S_{B}=\frac{R_{B}}{\varepsilon_{B}}
\end{gathered}
$$

where $P_{B}$ is the failure load $(\mathrm{N}) ; h$ and $b$ are the height and width of mid-span section of the specimen (mm); $d$ is the midspan deflection at flexural-tensile failure $(\mathrm{mm}) ; L$ is the span of the specimen (mm).

From formulas (1)-(3), the bending test results on fiber asphalt concrete at different temperatures, fiber volume ratios and fiber aspect ratios were obtained. The next step is to analyze how temperature, fiber volume ratio and fiber aspect ratio affect the flexural performance of asphalt concrete, according to the test results in Table 1.

Table 1. Bending test results

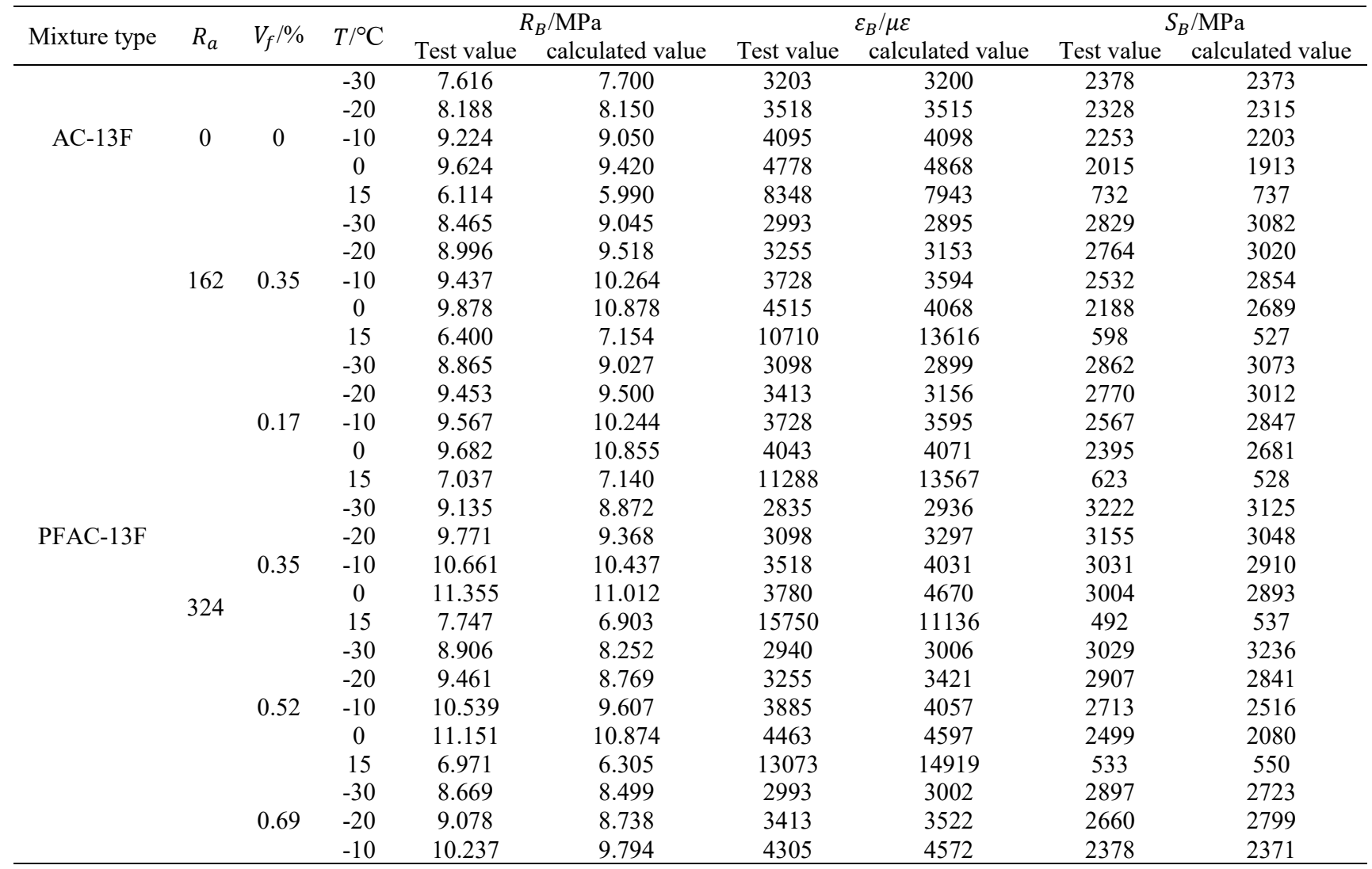




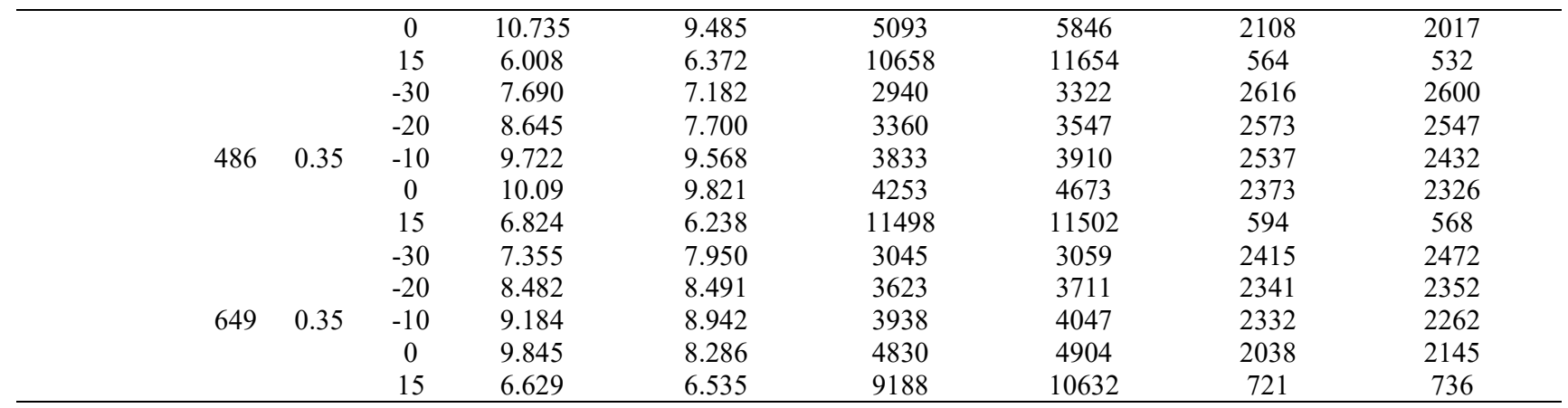

\section{EFFECTS OF TEMPERATURE ON FLEXURAL- TENSILE PERFORMANCE OF FIBER ASPHALT CONCRETE}

\subsection{Flexural-tensile strength}

It can be seen from Table 1 that, as the temperature changed from $-30{ }^{\circ} \mathrm{C}$ to $15^{\circ} \mathrm{C}$, the flexural-tensile strengths of the base asphalt concrete (AC-13F) and polyester fiber asphalt concrete (PFAC-13F) both increased first and then decreased, and peaked at the temperature of $0{ }^{\circ} \mathrm{C}$. Under this temperature, both types of asphalt concretes obviously softened under stress [18]. This is because temperature can change the mechanical performance of the asphalt, and thus determine the flexuraltensile failure mode of asphalt concrete. With the temperature growth from $-30{ }^{\circ} \mathrm{C}$ to $15{ }^{\circ} \mathrm{C}$, the brittle asphalt becomes viscoelastic and then plastic. The $0{ }^{\circ} \mathrm{C}$ is the division point between the brittle phase and the viscoelastic phase.
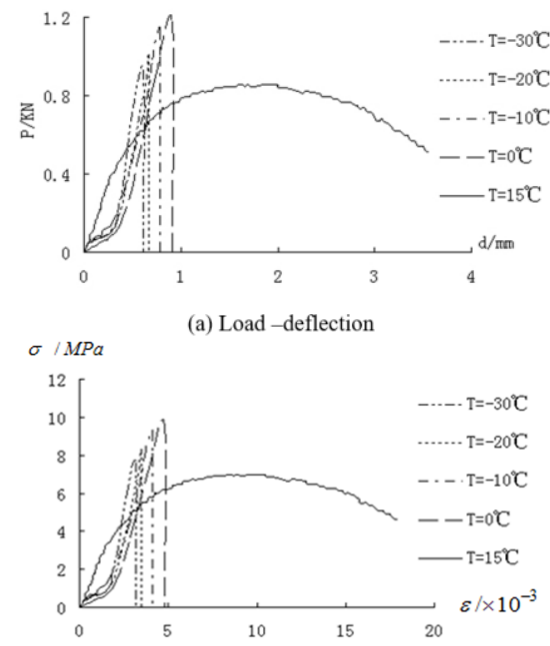

(b) Stress-strain
As shown in Figure 2, there was no obvious descending segment in the load-deflection curve and the stress-strain curve, when the temperature was below $0{ }^{\circ} \mathrm{C}$. During flexuralbending failure, brittle fractures appeared on the asphalt concrete. The lower the temperature, the more obvious the brittleness of the asphalt, and the poorer the resistance of asphalt concrete beam to flexural-tensile deformation. That is why fiber asphalt concrete beam had low flexural-tensile strength and failure load, when the temperature was at a low level. When the temperature was above $0{ }^{\circ} \mathrm{C}$, the asphalt became viscous, and the asphalt concrete suffered from bending plastic failure, as evidenced by the clear descending segments in the load-deflection curve and the stress-strain curve at the temperature of $15^{\circ} \mathrm{C}$. The higher the temperature, the weaker the fiber asphalt concrete in the viscoelastic phase, and the smaller the flexural-tensile strength and failure load.

As the temperature changed from $-30{ }^{\circ} \mathrm{C}$ to $15{ }^{\circ} \mathrm{C}$, the flexural-tensile strength of the fiber asphalt concrete increased first and then decreased. This trend can be illustrated as a quadratic curve:

$$
R_{B}=a_{0}+a_{1} T+a_{2} T^{2}
$$

The bending test data on fiber asphalt concretes were fitted nonlinearly to obtain the model parameters of formula (4) (Table 2) for fiber asphalt concretes of different fiber volume ratios and fiber aspect ratios. Next, the brittle temperatures of fiber asphalt concretes were derived from these model parameters. It can be seen that fiber asphalt concretes had a lower brittle temperature than base asphalt concretes; the lower the brittle temperature, the stronger the low-temperature crack resistance of fiber asphalt concrete; the optimal lowtemperature crack resistance was observed on the fiber asphalt concrete with the fiber aspect ratio of 324 and the fiber volume ratio of $0.35 \%$.

Figure 2. Ordinary asphalt concrete bending process

Table 2. Model parameters of formula (4)

\begin{tabular}{ccccccc}
\hline \multirow{2}{*}{ Mixture type } & $R_{a}$ & $V_{f} / \%$ & $a_{0}$ & $a_{1}$ & $a_{2}$ & Peak point temperature $/{ }^{\circ} \mathrm{C}$ \\
\hline AC-13F & 0 & 0 & 8.90 & -0.067 & -0.0097 & -3 \\
& 162 & 0.35 & 9.19 & -0.093 & -0.0065 & -7 \\
& & 0.17 & 9.28 & -0.088 & -0.0087 & -5 \\
PFAC-13F & 324 & 0.35 & 10.55 & -0.093 & -0.0061 & -8 \\
& & 0.52 & 10.26 & -0.103 & -0.0078 & -7 \\
& & 0.69 & 9.77 & -0.105 & -0.0088 & -6 \\
& 486 & 0.35 & 9.52 & -0.088 & -0.0075 & -6 \\
\hline
\end{tabular}




\subsection{Failure strain}

It can be seen from Table 1 that the failure strain of fiber asphalt concrete increased with temperature. This trend can be attributed to the following facts: When the temperature is below $0{ }^{\circ} \mathrm{C}$, the asphalt is highly brittle, and the fiber asphalt concrete exhibits obvious elasticity. The lower the temperature, the more elastic the fiber asphalt concrete, and the smaller the deflection and strain at flexural-tensile failure. When the temperature is above $0{ }^{\circ} \mathrm{C}$, the asphalt is highly viscous, and the fiber asphalt concrete exhibits obvious viscoelasticity. The higher the temperature, the more viscoelastic the fiber asphalt concrete, and the greater the deflection and strain at flexuraltensile failure.

When the temperature was equal to or smaller than $0{ }^{\circ} \mathrm{C}$, the failure strain of fiber asphalt concrete increased linearly with the rising temperature. The linear relationship can be expressed as:

$$
\varepsilon_{B}=a+b T
$$

where $\mathrm{a}$ and $\mathrm{b}$ are two parameters about the relationship between the failure strain of fiber asphalt concrete and temperature.

The bending test data on polyester fiber asphalt concretes were fitted nonlinearly to obtain the model parameters of formula (5) for fiber asphalt concretes. The results show that a and $b$ first increased and then decreased with the growth in fiber volume ratio and fiber aspect ratio. The two parameters minimized at the fiber volume ratio of $0.35 \%$ and the fiber aspect ratio of 324. In this case, the time-failure strain curve of polyester fiber asphalt concrete remained at a low level, indicating that the polyester fibers fully restrain deformation at low temperatures and that polyester fiber asphalt concrete is not sensitive to temperature changes.

Table 3. Model parameters of formula (5) and brittle temperatures

\begin{tabular}{cccccc}
\hline \multirow{2}{*}{ Mixture type } & $R_{a}$ & $V_{f} / \%$ & $a$ & $b$ & $R^{2}$ \\
\hline AC-13F & 0 & 0 & 4694 & 53.2 & 0.9757 \\
& 162 & 0.35 & 4379 & 50.4 & 0.9481 \\
& & 0.17 & 4043 & 34.5 & 0.9989 \\
PFAC-13F & 324 & 0.35 & 3796 & 32.6 & 0.9907 \\
& & 0.52 & 4416 & 52.0 & 0.9825 \\
& 486 & 0.69 & 5030 & 71.9 & 0.9809 \\
& 649 & 0.35 & 4258 & 44.1 & 0.9994 \\
& & & & & \\
\hline
\end{tabular}

\subsection{Failure brittleness modulus}

It can also be seen from Table 1 that the failure brittleness modulus of polyester fiber asphalt concrete is negatively correlated with temperature. The negative correlation was obviously linear when the temperature was below $0{ }^{\circ} \mathrm{C}$, and was extremely significant when the temperature was above $0{ }^{\circ} \mathrm{C}$. A possible reason is provided as follows: When the temperature was below $0{ }^{\circ} \mathrm{C}$, the flexural-tensile failure of fiber asphalt concrete was clearly elastic. The lower the temperature, the smaller the failure deformation of the fiber asphalt concrete in the elastic phase, and the greater the failure brittleness modulus. When the temperature was above $0{ }^{\circ} \mathrm{C}$, the flexural-tensile failure of fiber asphalt concrete was clearly viscoelastic. The higher the temperature, the greater the failure deformation of the fiber asphalt concrete in the viscoelastic phase, and the smaller the failure brittleness modulus.

\section{EFFECTS OF FIBER VOLUME RATIO ON FLEXURAL-TENSILE PERFORMANCE OF FIBER ASPHALT CONCRETE}

\subsection{Flexural-tensile strength}

As shown in Table 1, the flexural-tensile strength of polyester fiber asphalt concrete increased first and then decreased with the growth in fiber volume ratio, when the temperature remained the same, and peaked at the fiber volume ratio of $0.35 \%$. There are two causes of this particular trend.

First, it can be seen from Figure 3 that the fiber asphalt concrete mainly cracked along the interface between particles during flexural-tensile failure. The flexural-tensile resistance of asphalt concrete mainly depends on the strength of the asphalt-aggregate interface [11]. The proper addition of fibers to the base asphalt mixture increases the OAC and the thickness of the asphalt membrane. Meanwhile, the fibers can adsorb and infiltrate the light components of the asphalt, and form chemical bonds with these components. In this way, the fibers enhance the asphalt-aggregate interface, and thus improving the flexural-tensile strength of asphalt concrete [14].

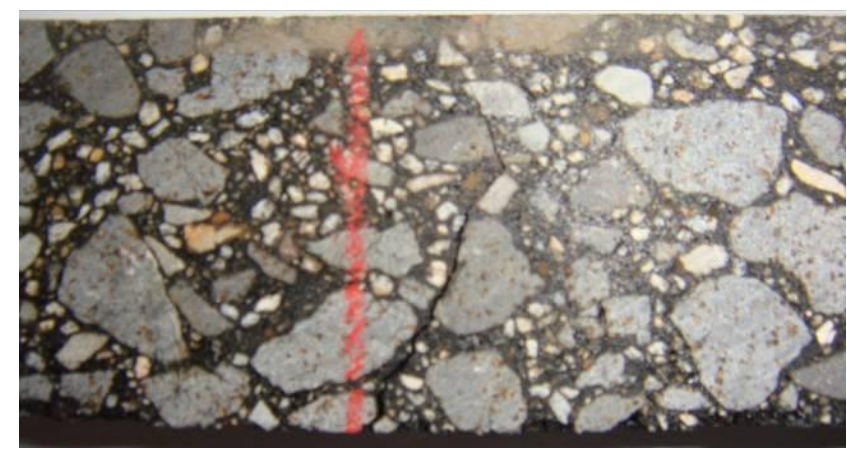

Figure 3. Bending failure crack development form

Second, the fibers of a proper volume ratio can disperse uniformly in the asphalt concrete, creating a 3D fiber network. The density of the fiber network bears on how much the fibers can restrain the flexural-tensile deformation of asphalt concrete. Within a proper range, the greater the fiber volume ratio, the denser the fiber network, the greater the restraining effect, and the stronger the asphalt concrete. Of course, the fiber volume ratio should not surpass the maximum number of fibers that can be contained in the fiber network. Otherwise, the fibers will become less dispersive and accumulate in local areas of the fiber network, forming bundles and cakes. These defects will lower the flexural-tensile strength of the asphalt concrete. During our tests, the flexural-tensile strength of fiber asphalt concrete was lower than that of base asphalt concrete, when the polyester fiber reached the fiber volume ratio of $0.69 \%$.

\subsection{Failure strain}

It can be seen from Table 1 that, when the temperature 
remained unchanged below $0{ }^{\circ} \mathrm{C}$, the failure strain of fiber asphalt concrete decreased first and then increased with the growth in fiber volume ratio, and the fracture-tensile failure of fiber asphalt concrete was minimized at the polyester fiber volume ratio of $0.35 \%$; when the temperature stood at $15{ }^{\circ} \mathrm{C}$, the failure strain of fiber asphalt concrete increased first and then decreased with the growth in fiber volume ratio, and the fracture-tensile failure of fiber asphalt concrete was maximized at the polyester fiber volume ratio of $0.35 \%$. Below are the possible explanations of these trends.

When the temperature is below $0{ }^{\circ} \mathrm{C}$, brittle fractures emerge on the asphalt concrete during the flexural-tensile failure, while the fibers are mainly broken under the tensile force [14]. Within a proper range, the greater the fiber volume ratio, the denser the fiber network, the greater the restraining effect of fibers on the flexural-tensile deformation of asphaltconcrete. However, an excessively high fiber volume ratio will reduce the strength of asphalt concrete and weaken the restraining effect of fibers, such that the failure strain of fiber asphalt concrete increases during low-temperature brittle failure.

When the temperature remains at $15^{\circ} \mathrm{C}$, the fiber asphalt concrete is highly viscoelastic, the fiber asphalt concrete beam mainly suffers from plastic damages during flexural-tensile failure, and the fibers are mostly damaged by slippage. During interface slippage, the fibers can prevent crack extension. The extent of fibers is positively correlated with the failure strain and the resistance of fiber asphalt concrete to flexural-tensile failure. The crack arresting ability of fibers mainly depends on the fiber volume ratio. Within a proper range, a high fiber volume ratio means more fibers per unit volume of asphalt concrete, and a high density of the uniformly distributed fiber network. As a result, there will be many longitudinal fibers on the beam section under flexural-tensile failure, under a high fiber volume ratio. The fibers will bear a high tensile stress as they slide along the interface, thereby slowing down the crack extension and pushing up the failure strain of asphalt concrete. If the fiber volume ratio is too high, however, the fibers will accumulate in local areas of the fiber network and form defects in the asphalt concrete. The flexural-tensile stress will concentrate in these defected places, reducing the bearing capacity of the asphalt concrete. That is why the failure strain of asphalt concrete decreased in our tests.

\subsection{Failure stiffness modulus}

It can also be seen from Table 1 that, when the temperature was below $0{ }^{\circ} \mathrm{C}$, the failure stiffness modulus of fiber asphalt concrete increased first and then decreased with the growth of fiber volume ratio, and peaked at the polyester fiber volume ratio of $0.35 \%$; in this case, the fiber asphalt concrete exhibited good low-temperature crack resistance. When the temperature was at $15{ }^{\circ} \mathrm{C}$, the failure stiffness modulus of fiber asphalt concrete decreased first and then increased with the growth of fiber volume ratio, and minimized at the polyester fiber volume ratio of $0.35 \%$; in this case, the fiber asphalt concrete boasted good flexural and tensile performance.

The reason is that, when the fiber asphalt concrete is brittle at low temperature, a proper fiber volume ratio helps restrain the deformation of the asphalt concrete. The restraining effect increases with the fiber volume ratio, but declines when the fiber volume ratio is excessively high. As mentioned before, too many fibers will accumulate in local areas, forming cakeshaped defects, and these defects will reduce the effect of fibers on restraining deformation.

When the temperature reaches $15^{\circ} \mathrm{C}$, the fiber asphalt concrete may suffer from plastic damages under flexuraltensile stress. In this case, the fibers mainly prevent crack extension with the tensile stress from interface slippage. The greater the prevention ability, the larger the failure strain of fiber asphalt concrete beam. Under the same fiber aspect ratio, the prevention ability increases with the fiber volume ratio, but decreases when there are too many fibers. As a result, the failure stiffness modulus in our tests increased first and then decreased with the growth of fiber volume ratio.

\section{EFFECTS OF FIBER ASPECT RATIO ON FLEXURAL-TENSILE PERFORMANCE OF FIBER ASPHALT CONCRETE}

\subsection{Flexural-tensile strength}

As can be seen from Table 1, the flexural-tensile strength of polyester fiber asphalt concrete increased first and then decreased with the growth of fiber aspect ratio, when the temperature remained the same. The maximum flexuraltensile strength appeared at the fiber aspect ratio of 324, under which the fiber asphalt concrete showed good flexural-tensile performance. These results can be explained by the following facts.

When the fiber diameter and fiber volume ratio remain constant, the fibers tend to be longer and point to different directions under a high fiber aspect ratio. In this case, the fibers are highly likely to curl in the asphalt concrete, forming cakeshaped defects [14], which dampens the enhancement effect of fibers. Under the same conditions, a small fiber aspect ratio means each fiber is relatively short, and more fibers exist per unit volume of asphalt concrete. Then, the fibers will become less dispersive and form cake defects in the asphalt concrete, which reduces the enhancement effect of fibers. Under the polyester fiber aspect ratio of 324 , the fibers will neither curl into cakes due to the excessive length nor form cake defects due to the numerous fibers per unit volume of concrete. As a result, the fiber asphalt concrete will achieve a good flexuraltensile performance when the fiber aspect ratio is 324 .

\subsection{Failure strain}

It can be seen from Table 1 that, when the temperature remained unchanged below $0{ }^{\circ} \mathrm{C}$, the failure strain of fiber asphalt concrete decreased first and then increased with the growth in fiber aspect ratio, and reached the minimum at the fiber aspect ratio of 324; in this case, the fiber asphalt concrete enjoyed a good flexural-tensile performance. When the temperature stood at $15^{\circ} \mathrm{C}$, the failure strain of fiber asphalt concrete increased first and then decreased with the growth in fiber aspect ratio, and reached the maximum at the fiber aspect ratio of 324 ; in this case, the fiber asphalt concrete also enjoyed a good flexural-tensile performance.

When the temperature is below $0^{\circ} \mathrm{C}$, brittle fractures form on the asphalt concrete during the flexural-tensile failure. The flexural-tensile deformation of the asphalt concrete is restrained by the fibers, which bear lots of tensile stress. Under the fixed fiber volume ratio and fiber diameter, each fiber is relatively long at a high fiber aspect ratio. In this case, there will be relatively few fibers per unit volume of asphalt concrete, and thus limited number of longitudinal fibers on the 
beam section under flexural-tensile failure. Therefore, the fibers' restraining effect on the flexural-tensile deformation of asphalt concrete will decrease. The high fiber aspect ratio also means the fibers tend to point to different directions, making it easy for fibers in the asphalt concrete to curl into cakes and reduce the restraining effect of the fiber network.

Under the fixed fiber volume ratio and fiber diameter, each fiber is relatively short at a low fiber aspect ratio. In this case, there will be many fibers per unit volume of asphalt concrete, leading to nonuniform dispersion of the fibers. It is highly likely for fibers to accumulate in local areas of the fiber network in the asphalt concrete, which undermines the restraining effect of the fiber network on concrete deformation In addition, the tensile strength of short fibers often exceeds the interface strength. The fibers are pulled out along the interface, causing slippage damages. Thus, the fibers will become less efficient in restraining concrete deformation. The optimal restraining effect appears at the fiber aspect ratio of 324 , which corresponds to the minimum failure strain of fiber asphalt concrete.

When the temperature remains at $15^{\circ} \mathrm{C}$, the fiber asphalt concrete beam mainly suffers from plastic damages during flexural-tensile failure, and the fibers are mostly damaged by slippage along the interface. During interface slippage, the fibers' ability to prevent crack extension is positively correlated with the failure strain of the fiber asphalt concrete. If the fiber aspect ratio is high, each fiber will be relatively long and bear a high tensile stress in interface slippage, and will be more likely to break. If the fiber aspect ratio is low, each fiber will be relatively short and get pulled out early in interface slippage. Once pulled out, the fiber will no longer bear the tensile stress. Then, the cracks will propagate quickly, causing flexural-tensile failure of the asphalt concrete.

\subsection{Failure stiffness modulus}

It can also be seen from Table 1 that, when the temperature was below $0{ }^{\circ} \mathrm{C}$, the failure stiffness modulus of fiber asphalt concrete increased first and then decreased with the growth of fiber aspect ratio, and peaked at the fiber aspect ratio of 324 ; in this case, the fiber asphalt concrete demonstrated good flexural-tensile performance. When the temperature was at $15^{\circ} \mathrm{C}$, the failure stiffness modulus of fiber asphalt concrete decreased first and then increased with the growth of fiber aspect ratio, and minimized at the fiber aspect ratio of 324 ; in this case, the fiber asphalt concrete also displayed good flexural-tensile performance.

The reason is that, when the temperature is below $0{ }^{\circ} \mathrm{C}$, the asphalt concrete may suffer from low-temperature brittle damages under the flexural-tensile stress. The fibers can bear a part of the stress to restrain the concrete deformation. Within a proper range, the restraining effect increases with the fiber aspect ratio. If the fiber aspect ratio is excessively high, however, the fibers will curl into cake defects, and become less effective in restraining the flexural-tensile deformation. That is why the failure stiffness modulus of fiber asphalt concrete increased first and then decreased with the growth of fiber aspect ratio, when the temperature was below $0{ }^{\circ} \mathrm{C}$.

When the temperature reaches $15^{\circ} \mathrm{C}$, the fiber asphalt concrete, which belongs to the viscoelastic phase, may suffer from plastic damages under flexural-tensile stress. In this case, the fibers mainly prevent crack extension with the tensile stress from interface slippage. The greater the prevention ability, the larger the failure strain of fiber asphalt concrete beam. Under the same fiber volume ratio, the fibers tend to slip along the interface at a small fiber aspect ratio and rupture at a large fiber aspect ratio. In either case, the fibers will become less efficient in restraining crack extension, dragging down the resistance of fiber asphalt concrete to flexural-tensile deformation. As a result, the failure stiffness modulus of fiber asphalt concrete decreased first and then increased with the growth of fiber aspect ratio, when the temperature was at $15^{\circ} \mathrm{C}$.

\section{FCFP-BASED CALCULATION OF FLEXURAL- TENSILE PERFORMANCE OF ASPHALT CONCRETE}

The above analysis shows that fiber volume ratio and fiber aspect ratio both have significant impacts on the flexuraltensile performance of asphalt concrete, and their influence laws are basically consistent. As shown in Table 1, the test results agree well with the fitted results. Therefore, the FCFP $\lambda_{f}=V_{f} \times R_{a}$ was introduced to describe the combined effect of fiber volume ratio and fiber aspect ratio on the flexuraltensile performance of asphalt concrete. Whichever the temperature, fiber volume ratio and fiber aspect ratio, the flexural-tensile strength of polyester fiber asphalt concrete always increases and then decreases with the growth of the FCFP. Through the nonlinear fitting of our test results, the relationship between the flexural-tensile strength of polyester fiber asphalt concrete and the FCFP can be expressed as:

$$
\begin{array}{ll}
\boldsymbol{R}_{B}=7.7+3.71 \lambda_{f}-2.36 \lambda_{f}^{2} & \mathrm{~T}=-30^{\circ} \mathrm{C} \\
\boldsymbol{R}_{B}=8.15+3.75 \lambda_{f}-2.36 \lambda_{f}^{2} & \mathrm{~T}=-20^{\circ} \mathrm{C} \\
\boldsymbol{R}_{B}=9.05+3.06 \lambda_{f}-1.62 \lambda_{f}^{2} & \mathrm{~T}=-10^{\circ} \mathrm{C} \\
\boldsymbol{R}_{B}=9.42+3.74 \lambda_{f}-2.06 \lambda_{f}^{2} & \mathrm{~T}=0^{\circ} \mathrm{C} \\
\boldsymbol{R}_{B}=5.99+3.30 \lambda_{f}-2.20 \lambda_{f}^{2} & \mathrm{~T}=15^{\circ} \mathrm{C}
\end{array}
$$

In the elastic phase, the failure strain of fiber asphalt concrete decreases first and then increases with the growth of the FCFP. In the viscoelastic phase, however, the failure strain of fiber asphalt concrete increases first and then decreases with the growth of the FCFP. Through the nonlinear fitting of our test results, the relationship between the failure strain of polyester fiber asphalt concrete and the FCFP under different temperatures can be expressed as:

$$
\begin{array}{cc}
\varepsilon_{B}=3200-842.04 \lambda_{f}+537.20 \lambda_{f}^{2} & \mathrm{~T}=-30^{\circ} \mathrm{C} \\
\varepsilon_{B}=3515-1084.22 \lambda_{f}+\mathbf{7 8 6 . 5 7} \lambda_{f}^{2} & \mathrm{~T}=-20^{\circ} \mathrm{C} \\
\varepsilon_{B}=4098-1719.03 \lambda_{f}+1463.94 \lambda_{f}^{2} & \mathrm{~T}=-10^{\circ} \mathrm{C} \\
\varepsilon_{B}=4868-2647.00 \lambda_{f}+2180.09 \lambda_{f}^{2} & \mathrm{~T}=0^{\circ} \mathrm{C} \\
\varepsilon_{B}=7943+17195.57 \lambda_{f}-12680.79 \lambda_{f}^{2} & \mathrm{~T}=15^{\circ} \mathrm{C}
\end{array}
$$

In the elastic phase, the failure stiffness modulus of fiber asphalt concrete increases and then decreases with the growth of the FCFP. In the viscoelastic phase, however, the failure stiffness modulus of fiber asphalt concrete decreases first and 
then increases with the growth of the FCFP. Through the nonlinear fitting of our test results, the relationship between the failure stiffness modulus of polyester fiber asphalt concrete and the FCFP under different temperatures can be expressed as:

$$
\begin{array}{cc}
S_{B}=2373+1926.98 \lambda_{f}-1192.00 \lambda_{f}^{2} & \mathrm{~T}=-30^{\circ} \mathrm{C} \\
S_{B}=2315+2016.99 \lambda_{f}-1364.07 \lambda_{f}^{2} & \mathrm{~T}=-20^{\circ} \mathrm{C} \\
S_{B}=2203+1936.18 \lambda_{f}-1391.24 \lambda_{f}^{2} & \mathrm{~T}=-10^{\circ} \mathrm{C} \\
S_{B}=1913+2312.85 \lambda_{f}-1666.18 \lambda_{f}^{2} & \mathrm{~T}=0^{\circ} \mathrm{C} \\
S_{B}=737-653.08 \lambda_{f}+497.95 \lambda_{f}^{2} & =15^{\circ} \mathrm{C}
\end{array}
$$

From formulas (12)-(26), it can be seen that the polyester fiber asphalt concrete enjoys good flexural-tensile performance when the FCFP amounts to 1.13.

\section{CONCLUSIONS}

The following conclusions were drawn from our bending tests on polyester fiber asphalt concretes:

(1) The flexural-tensile strength of fiber asphalt concrete increases first and then decreases with the rising temperature, and peaks at the temperature of $0{ }^{\circ} \mathrm{C}$. Under this temperature, the fiber asphalt concrete obviously softens under stress. Through nonlinear fitting, the author obtained the relationship between flexural-tensile strength of fiber asphalt concrete and temperature, which shows that the fibers can reduce the brittle temperature of the asphalt concrete.

(2) The failure strain of fiber asphalt concrete increases with temperature. When the temperature is below $0{ }^{\circ} \mathrm{C}$, the failure strain has an obvious linear relationship with temperature, while the failure stiffness modulus decreases with the rising temperature.

(3) Under different temperatures, the flexural-tensile strength of polyester fiber asphalt concrete increases first and then decreases with the growth in fiber volume ratio or fiber aspect ratio. When the fiber asphalt concrete suffers from lowtemperature brittle damages, the failure strain decreases first and then increases with the growth in fiber volume ratio or fiber aspect ratio, while the failure stiffness modulus increases first and then decreases with the growth in fiber volume ratio. When the fiber asphalt concrete suffers from plastic damages under flexural-tensile stress, the failure strain increases first and then decreases with the growth in fiber volume ratio or fiber aspect ratio, while the failure stress modulus decreases first and then increases with the growth in fiber volume ratio.

(4) The FCFP was introduced to describe the combined effect of fiber volume ratio and fiber aspect ratio on the flexural-tensile performance of asphalt concrete. The correlations of the FCFP with the flexural-tensile strength, failure strain and failure stiffness modulus of polyester fiber asphalt concrete can be expressed respectively by formulas (12)-(16), formulas (17)-(21) and formulas (22)-(26). The test results and theoretical analysis show that the optimal FCFP of polyester fibers is 1.13 .

The future research will probe deeper into the FCFP, a parameter reflecting the combined effect of fiber volume ratio and fiber aspect ratio on the flexural-tensile performance of asphalt concrete.

\section{ACKNOWLEDGMENT}

The authors gratefully acknowledge the financial support of the project from the Colleges and Universities Key Scientific Research Projects of Henan Province (Grant No. 17B580003) and Horizontal Research Project of Xuchang University (Grant No. 2017HX029 and 2019HX005).

\section{REFERENCES}

[1] Liang, C.Y., Li, Y.J. (2007). Effect of coarse aggregate shape on mechanical properties of asphalt mixture. Journal of China \& Foreign Highway, 27(5): 199-202. http://doi.org/10.3969/j.issn.1671-2579.2007.05.060j

[2] Shen, A.Q., Jiang, Q.H. (2004). Influencing factor and appraising on anti-cracking of asphalt mixture at low temperature. Journal of Chang'an University (Natural Science Edition), 24(5): 1-6. http://doi.org/10.3321/j.issn:1671-8879.2004.05.001

[3] Ge, Z.S., Huang, X.M., Xu, G.G. (2002). Evaluation of asphalt-mixture's low-temperature anti-cracking performance by curvature strain energy method. Journal of Southeast University (Natural Science Edition), 32(4): 653-655. http://doi.org/10.3321/j.issn:10010505.2002.04.026

[4] Zhang, M.K., Huang, X.M., Ren, Y.G. (2008). Using curvature strain energy to evaluate asphalt mixture's low temperature performance. Petroleum Asphalt, 22(5): 2023. http://doi.org/10.3969/j.issn.1006-7450.2008.05.005

[5] Yin, Y.M., Zhang, X.N., Zou, G.L. (2010). Investigation into low-temperature performance of asphalt mixtures based on glass transition temperature. Journal of South China University of Technology (Natural Science Edition), 38(10): 89-93. http://doi.org/10.3969/j.issn.1000-565X.2010.10.017

[6] Chen, J., Huang, X.M. (2012). Simulation of fracture process of asphalt mixture using three-dimension discrete element method. Journal of South China University of Technology (Natural Science Edition), 40(7): 21-26. http://doi.org/10.3969/j.issn.1000565X.2010.10.017

[7] Zhu, Z.H. (2004). Study on pavement performance of Asphalt mixture mixed with Fib. [Master thesis]. Xi An: Chang'an University. http://doi.org/10.7666/d.W029435

[8] Zheng, C.C., Guo, J.Y. (2005). Experiments of fracture behavior of glass fiber reinforced asphalt concrete. Journal of Chang'an University (Natural Science Edition), 26(3): 1-3. http://doi.org/10.3321/j.issn:16718879.2005 .03 .007

[9] Jiang, J., Pan, H.X., Wang, B. (2004). Study on crack resistance of fiber reinforced asphalt concrete. Journal of China \& Foreign Highway, 24(5): 111-113. http://doi.org/10.3969/j.issn.1671-2579.2004.05.032

[10] Tang, W., Sheng, X.J., Sun, L.J. (2008). Pavement performance of fiber reinforced asphalt mixture. Journal of Building Materials, 11(5): 612-615. http://doi.org/10.3969/j.issn.1007-9629.2008.05.019

[11] Chen, H.X., Zhang, Z.Q., Hu, C.S. (2004). Lowtemperature anti-cracking performance of fiberreinforced asphalt mixture. Journal of South China 
University of Technology (Natural Science Edition), 32(4): $\quad 82-86$. http://doi.org/10.3321/j.issn:1000565X.2004.04.019

[12] Dong, G., Zheng, N.X., Wang, J.F. (2015). Pavement performance of polyester fiber asphalt mortar and its mixture. Science \& Technology Review, 33(3): 49-53. http://doi.org/10.3981/j.issn.1000-7857.2015.03.007

[13] Wu, X.H., Zhang, D.L. (2005). Study of low temperature performance of fiber-enhanced asphalt concrete. Journal of Highway and Transportation Research and Development, 22(2): 7-9. http://doi.org/10.3969/j.issn.1002-0268.2005.02.003

[14] Zhang, J. (2012). Evaluation method of crack Resistance of Fiber reinforced Asphalt concrete based on bending strain Energy. Shanghai Highways, (3): 60-63. http://doi.org/10.3969/j.issn.1007-0109.2012.03.040
[15] Wang, J.C. (2007). Experiment on fracture behavior of fiber reinforced asphalt mixture. Journal of Kunming University of Science and Technology (Science and Technology), 32(6): 55-60. http://doi.org/10.3969/j.issn.1007-855X.2007.06.013

[16] Serfass, J.P., Samanos, J. (1996). Fiber-modified asphalt concrete characteristics, applications and behavior. Journal of the Association of Asphalt Paving Technologists, 65(1): 193-230.

[17] JTJ, 052-2011 Standard test methods of bitumen and bituminous mixtures for highway engineering.

[18] Chen, Y., Jiang, T., Huang, Z. Q., Fu, W.B. (2010). Effect of temperature on mechanical properties of asphalt concrete. Rock and Soil Mechanics, 31(7): 2192-2196. http://doi.org/10.3969/j.issn.1000-7598.2010.07.028 